\title{
Infrared Spectral Change in a Zinc Salt of an Ethylene-Methacrylic Acid Ionomer on Water Absorption
}

\author{
Tsutomu IsHIOKA \\ Department of Chemistry, Faculty of Science, Toyama University, \\ Gofuku, Toyama 930, Japan
}

(Received March 25, 1993)

\begin{abstract}
Local structural change in the ion aggregate in a zinc salt of poly(ethylene-comethacrylic acid) ionomer on water absorption-desorption process was investigated with use of infrared spectral change in the carboxylate antisymmetric stretch region. Three bands were found at 1539,1560 , and $1625 \mathrm{~cm}^{-1}$ in dried state. They collapsed into a singlet at $1587 \mathrm{~cm}^{-1}$ on swelling. The spectral change occurred reversibly with respect to the water content at a constant temperature. Analyzing the ratio of the relative integrated intensities of the dry state to the wet one, we evaluated the hydration number to a $\mathrm{Zn}^{2+}$ ion in the wet state. The difference in molar absorption coefficients of the bands between the dry and wet states can be explained by the vibrational coupling between the $v_{\mathrm{a}}\left(\mathrm{COO}^{-}\right)$and carboxylate rocking $\mathrm{P}\left(\mathrm{COO}^{-}\right)$modes.

KEY WORDS Zn Salt of Ethylene-Methacrylic Acid Ionomer / Infrared Spectra / Water Absorption/Ion-Aggregates /
\end{abstract}

A series of copolymers of ethylene (E) and methacrylic acid (MA), where the MA units are partially or fully neutralized with such a metal cation as $\mathrm{Na}$ or $\mathrm{Zn}$, is known under the trade name of Surlyn of E. I. du Pont de Nemours and Co., Inc. as an ionomer. In bulk samples of ionomer, the ionic groups tend to gather and form ion aggregates on neutralization. The molecular level structure of the aggregate has been studied with various experimental methods. Eisenberg postulated that there are two types of ion aggregate in some ionomers. ${ }^{1,2}$ At low ion concentration (below 5-6 mol\%) aggregation of a few ionic units called "multiplet" is formed. The multiplet consists of only ionic groups and does not contain hydrocarbon chains. When the ion concentration becomes sufficiently high (above 5-6mol\%), association of the multiplet occurs, forming cluster where the constituents are separated from each other by non-ionic matrix.

In order to elucidate the internal structure of multiplet or ion cluster, various spectroscopic studies have been performed. Ion concentration dependence of far-infared spec$\operatorname{tra}^{3,4}$ and low-frequency Raman spectra ${ }^{5-7}$ in polystyrene-based ionomers were investigated and some characteristic bands were assigned to the translational vibrations of the cation in anionic electrostatic field in either multiplet or ion cluster. As for the vibrations of the anionic groups, the carboxylate antisymmetric stretch $v_{\mathrm{a}}\left(\mathrm{COO}^{-}\right)$mode was found to be sensitive to the amount of hydration and the coordination structure. Brozoski et al. investigated extensively the $v_{\mathrm{a}}$ $\left(\mathrm{COO}^{-}\right)$infrared spectra of E-MA ionomers with various water contents. ${ }^{8-11}$ In a dry state, splitting of the $v_{\mathrm{a}}\left(\mathrm{COO}^{-}\right)$band was observed for $\mathrm{Na}, \mathrm{Mg}, \mathrm{Ca}, \mathrm{Sr}$, and $\mathrm{Ba}$ salts but not for $\mathrm{K}, \mathrm{Cs}$, and $\mathrm{Zn}$ salts. The split was considered to be indicative of the existence of a locally ordered structure (multiplet). Several $v_{\mathrm{a}}\left(\mathrm{COO}^{-}\right)$bands were tentatively assigned to those of multiplet or cluster. They also studied 
temperature dependence of the infrared bands due to the $\mathrm{C}-\mathrm{O}$ stretch of the carbonyl and carboxylate groups for a partially neutralized $\mathrm{Zn}$ salt of an E-MA ionomer. ${ }^{12}$ With an increase in temperature, the three carboxylate stretching bands at 1620,1565 , and $1536 \mathrm{~cm}^{-1}$ increased in intensity, while the band at $1585 \mathrm{~cm}^{-1}$ decreased. They interpreted that this was caused by the change in the coordination structure of the carboxylate groups and assigned the $1620 \mathrm{~cm}^{-1}$ band to zinc acid salt, the 1565 and $1536 \mathrm{~cm}^{-1}$ bands to hexacoordinated zinc carboxylate, and the $1585 \mathrm{~cm}^{-1}$ band to tetracoordinated zinc carboxylate.

We have also observed the same splitting of the carboxylate antisymmetric stretch band for a partially neutralized $\mathrm{Zn}$ salt of an E-MA ionomer with an increase in temperature ${ }^{13}$ but the spectral change was not reversible with respect to the temperature. Thereafter, we have found that the spectral change was essentially induced by the change in water content, not by the change in temperature. The spectral change occurred even at low temperature of $60^{\circ} \mathrm{C}^{14,15}$ From the analysis of the small-angle $\mathrm{X}$-ray scattering profile for the same sample, the dimension of the ion aggregate was estimated as about $10 \AA$ (core diameter 7.6-8.0 $\AA$, shell diameter $16.8-15.0 \AA$ ), indicating that the aggregate was recognized as multiplet. In this paper, in order to characterize intra-multiplet structure, the spectral change for a zinc salt of an E-MA ionomer with moisture content is discussed. The difference between our interpretation of the spectral change and that of Coleman et al. is stated.

\section{EXPERIMENTAL}

The sample of a partially neutralized $\mathrm{Zn}$ salt of E-MA ionomer (referred to as E-MA-Zn, Surlyn 472) was the same as that described before. ${ }^{15}$

Infrared spectra were measured with JASCO A-3 and JEOL JIR-100 FT-IR spectropho- tometers with resolutions of $2.6 \mathrm{~cm}^{-1}$ and $4 \mathrm{~cm}^{-1}$, respectively.

Experiment of moisture absorption of the specimen used for the IR measurements was carried out in a desiccator held at $60.0 \pm 0.05^{\circ} \mathrm{C}$ under the saturated vapor pressure. The experiment was also carried out at $40.0^{\circ} \mathrm{C}$ but the result was the same with that at $60.0^{\circ} \mathrm{C}$. Therefore, only that at $60.0^{\circ} \mathrm{C}$ was described below. Film specimens for IR measurements were dried first at $41.0^{\circ} \mathrm{C}$ under vacuum $\left(10^{-3}\right.$ Torr) over 2 weeks until they approached to their respective constant weight, i.e., to the "equilibrium dried weight". These dried sample still contained residual water. The "absolutely dry weight" was estimated by an extrapolation of the infrared intensities as will be described below. Then, the film specimens were subjected to moisture absorption-desorption process at $60.0^{\circ} \mathrm{C}$. To keep the degree of crystallinity of the sample constant throughout the measurement, the films were annealed beforehand at $60.0^{\circ} \mathrm{C}$ over $10 \mathrm{~h}$, and the absorption-desorption procedure was carried out at the same temperature. The equilibrium was achieved over $30 \mathrm{~h}$. The amount of water absorbed by the specimens was weighed using a Mettler B-6 balance with the sensitivity $10^{-5} \mathrm{~g}$ in an open state. The weight loss or gain of the sample during the measurement was confirmed to be negligible.

\section{RESULTS AND DISCUSSION}

On the moisture absorption-desorption process a substantial spectral change was observed in the $1500-1650 \mathrm{~cm}^{-1}$ region (Figure 1). At the water content $(\mathrm{w})$ of $0.03 \mathrm{wt} \%$ (the value is based on the "equilibrium dried state"), there appear plural bands assigned to the $v_{\mathrm{a}}\left(\mathrm{COO}^{-}\right)$ mode. As $w$ increases to $0.24 \mathrm{wt} \%$, these bands tend to collapse each other into one band centered at $1587 \mathrm{~cm}^{-1}$. This spectral change occurs reversibly with respect to the change in the water content at a constant temperature.

The IR absorption curve was separated into 


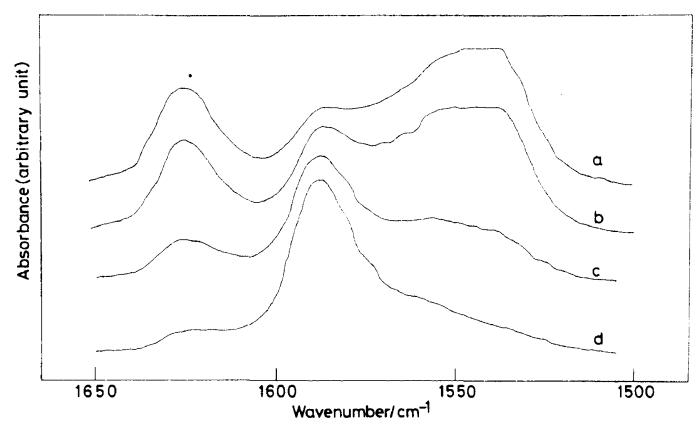

Figure 1. Change of contours in $v_{\mathrm{a}}\left(\mathrm{COO}^{-}\right)$region for E-MA- $\mathrm{Zn}$ at various $\mathrm{H}_{2} \mathrm{O}$ wt \%, (a) $0.03 \%$, (b) $0.09 \%$, (c) $0.13 \%$, (d) $0.24 \%$.

four bands by assuming a Gaussian+Lorentzian function for each band, expressed as

$$
\begin{aligned}
I(v)= & h_{1} \exp \left\{-\ln 2\left[\left(v-v_{0}\right) / \sigma\right]^{2}\right\} \\
& +h_{2} \sigma^{2} /\left[\left(v-v_{0}\right)^{2}+\sigma^{2}\right]
\end{aligned}
$$

where $v_{0}$ is the peak position. Here, the slitfunction distortion and the contribution of asymmetric component were not considered. The Gaussian and Lorentzian components have the peak heights of $h_{1}$ and $h_{2}$, respectively. In order to reduce the number of adjustable parameters, the two components are assumed to have the same half-width $\sigma$. Two peaks at $1625 \mathrm{~cm}^{-1}$ (at $w=0.03 \%$ ) and at $1587 \mathrm{~cm}^{-1}$ (at $w=0.24 \%$ ) are easily distinguished from other peaks. The two bands have almost the same half-width. By the trial and error method, the observed spectra for the four water contents were reproduced by assuming four bands centered at $1625,1587,1560$, and $1539 \mathrm{~cm}^{-1}$ having nearly the same half-width. The ratio of the Lorentzian/Gaussian components $\left(h_{2} /\right.$ $h_{1}$ ) was fixed to 4.10 for every band and the relative heights $\left(h_{2}\right)$ of the three bands at 1539 , 1560 , and $1625 \mathrm{~cm}^{-1}$ were fixed at $9: 8: 7$. The ratio was confirmed to remain constant independently of the water content. In other words, the intensities of these bands vary (increase with a decrease in water content) in a parallel way. Therefore, the triplet should be associated with a certain specific structure of
Table I. $h_{2}$ and $\sigma$ of the four bands at 1539, 1560, 1587 , and $1625 \mathrm{~cm}^{-1}$ at various water contents.

( ) is referred to "absolutely dried weight".

\begin{tabular}{lllllll}
\hline & & $v / \mathrm{cm}^{-1}$ & 1539 & 1560 & 1587 & 1625 \\
& & $\sigma / \mathrm{cm}^{-1}$ & 11.8 & 11.8 & 11.2 & 10.2 \\
\cline { 3 - 6 } & & & $h_{2}$ & & \\
$\mathrm{H}_{2} \mathrm{O} w \mathrm{t} \%$ & & & & & \\
\hline \multirow{2}{*}{0.03} & $(0.17)$ & & 9.56 & 8.50 & 5.40 & 7.44 \\
0.09 & $(0.23)$ & 9.00 & 8.00 & 7.80 & 7.00 \\
0.13 & $(0.27)$ & 3.94 & 3.50 & 9.80 & 3.06 \\
0.24 & $(0.38)$ & & 2.48 & 2.20 & 14.00 & 1.93 \\
\hline
\end{tabular}

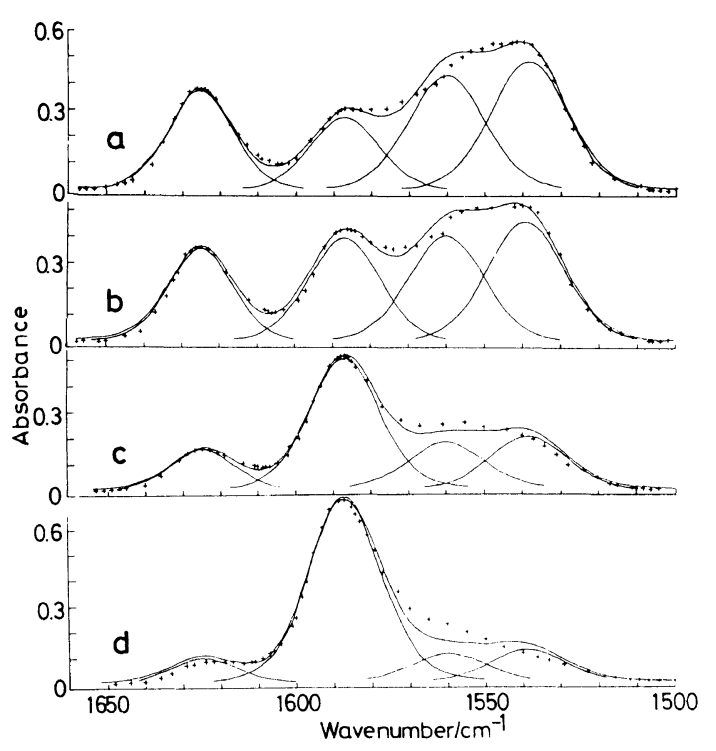

Figure 2. Separated contours of $v_{\mathrm{a}}\left(\mathrm{COO}^{-}\right)$for E-MA$\mathrm{Zn}$ at various $\mathrm{H}_{2} \mathrm{O}$ wt \%, (a) $0.03 \%$, (b) $0.09 \%$, (c) $0.13 \%$, (d) $0.24 \%$. +, obsd., - , calcd.

the carboxylate groups in the dry state. On the other hand, the singlet at $1587 \mathrm{~cm}^{-1}$ whose intensity increases with an increase in the water content should be associated with the carboxylate groups in the moistened state. The parameters used were listed in Table I. The resultant band separations were shown in Figure 2. A little discrepancies between the observed and calculated spectra at 1560 and $1539 \mathrm{~cm}^{-1}$ arose especially in higher water contents (Figure 2(c), (d)), indicating that the relative heights of the three bands at 1539,1560 , 
and $1625 \mathrm{~cm}^{-1}$ slightly differed from $9: 8: 7$. This discrepancies may result from the asymmetric band profile of the singlet (1587 $\mathrm{cm}^{-1}$ ) having a tail to low frequency side caused by the vibrational interaction between the $\mathrm{COO}^{-}$groups and the $\mathrm{H}_{2} \mathrm{O}$ molecules absorbed, but a precise explanation was not examined at the present stage.

Here, the interpretation of the origins of the triplet and the singlet presented by Coleman et $a l .{ }^{12}$ should be stated. They assigned the band at $1625 \mathrm{~cm}^{-1}$ to zinc acid salt structure, those at 1560 and $1539 \mathrm{~cm}^{-1}$ to hexacoordinated zinc carboxylate, and that at $1587 \mathrm{~cm}^{-1}$ to tetracoordinated zinc carboxylate and interpreted that the spectral change was caused by the thermally induced change of the coordination structure. On the contrary, our results show that the spectral change occurs with the change in the moisture content even at a constant temperature of $40^{\circ} \mathrm{C}$. Hence, the spectral change found with an increase in temperature should be ascribed to the desorption of moisture. Second, the result of the band separation indicates that the intensity change of the triplet at 1539,1560 , and $1625 \mathrm{~cm}^{-1}$ occurred in a parallel way. Therefore these bands at 1560 and $1539 \mathrm{~cm}^{-1}$ and that at $1625 \mathrm{~cm}^{-1}$ are suggested to be assigned to a same structural entity.

By using relative integrated intensities of the triplet and the singlet, the equilibrium between the dry and the wet state was considered. The integrated intensities of the dry and wet states are denoted by $K_{\text {dry }}$ and $K_{\text {wet }}$, respectively. If the thickness and the density of the film are kept constant on the moisture absorption, $K_{\mathrm{dry}}$ is expressed as

$$
K_{\mathrm{dry}}=\varepsilon_{\mathrm{dry}} x_{\mathrm{dry}}
$$

where $\varepsilon_{\text {dry }}$ denotes the integrated molar absorption coefficient of the triplet and $x_{\mathrm{dry}}$ the molar fraction of the $\mathrm{COO}^{-}$groups in the dry state. Similarly for the wet state

$$
K_{\text {wet }}=\varepsilon_{\text {wet }}\left(1-x_{\text {dry }}\right)
$$

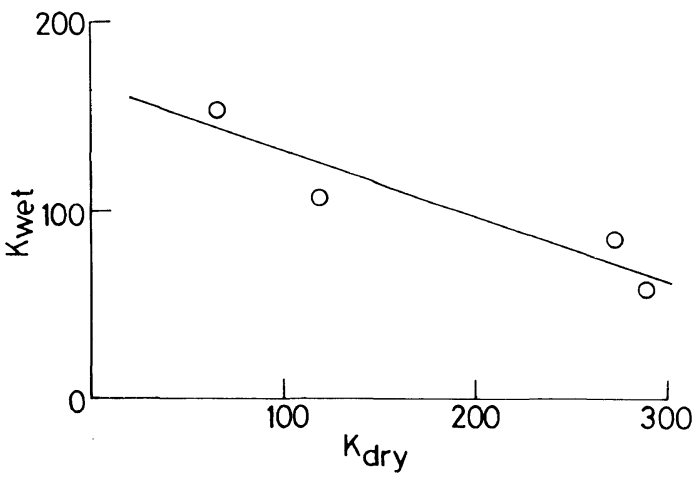

Figure 3. Relation between relative integrated intensities of the triplet ( $K_{\mathrm{dry}}$ in dry state) and the singlet ( $K_{\mathrm{wet}}$ in wet state) in the $v_{\mathrm{a}}\left(\mathrm{COO}^{-}\right)$region.

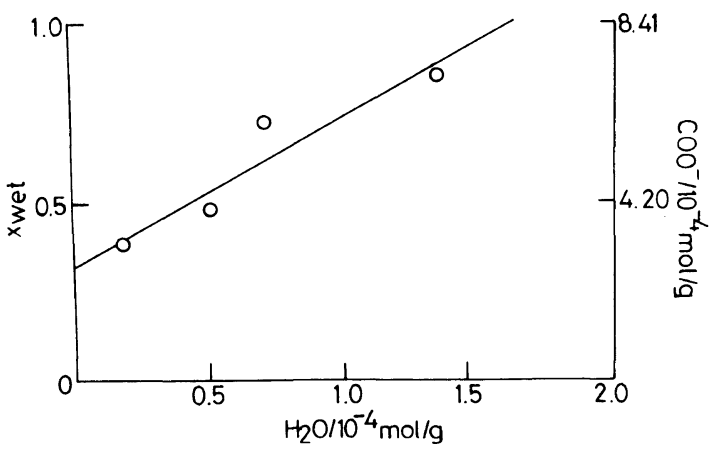

Figure 4. Relation between $x_{\text {wet }}$ (the molar fraction of the $\mathrm{COO}^{-}$groups in wet state) and the molar amount of $\mathrm{H}_{2} \mathrm{O}$ absorbed.

where $\varepsilon_{\text {wet }}$ denotes the molar absorption coefficient of the $1587 \mathrm{~cm}^{-1}$ band. With eq 2 and 3 , the following equation is obtained.

$$
K_{\text {wet }}=\varepsilon_{\text {wet }}-K_{\text {dry }}\left(\varepsilon_{\text {wet }} / \varepsilon_{\text {dry }}\right)
$$

Thus, the $K_{\text {wet }} v s . K_{\text {dry }}$ plot gives a straight line as shown in Figure 3. From the slope, the ratio $\varepsilon_{\text {wet }} / \varepsilon_{\text {dry }}$ is obtained as 0.343 . From eq 3 and 4 , $x_{\mathrm{dry}}$ is given as ${ }^{16}$

$$
x_{\mathrm{dry}}=1 /\left(1+K_{\mathrm{wet}} \varepsilon_{\mathrm{dry}} / K_{\mathrm{dry}} \varepsilon_{\mathrm{wet}}\right) .
$$

$x_{\mathrm{dry}}$ (or $x_{\text {wet }}=1-x_{\mathrm{dry}}$ ) for each water content (based on the equilibrium dried weight) is evaluated as shown in Figure 4. The intercept of the straight line on the negative side of the abscissa is considered to correspond to the amount of residual water in the equilibrium 
dried state. By adding this value $0.751 \times 10^{-4}$ $\mathrm{molg}^{-1}$ to the water content based on the "equilibrium dried weight", the water content based on the "absolutely dried weight" of the specimen can be obtained. From Figure 4, the hydration number to the ionic group in the wet state can be derived. The mole of the $\mathrm{COO}^{-}$ group in the wet state equals to $x_{\text {wet }}$ times the total mole of the $\mathrm{COO}^{-}$group in the sample, the latter being evaluated for the present specimen as $8.41 \times 10^{-4} \mathrm{~mol} \mathrm{~g}^{-1}$. From the line slope in Figure 4, the mole ratio $\left(\mathrm{COO}^{-} / \mathrm{H}_{2} \mathrm{O}\right)$ in the wet state is obtained as 3.56. This value indicates that in the wet state about one water molecule is absorbed per four carboxylate groups, or one $\mathrm{H}_{2} \mathrm{O}$ molecule is absorbed per two $\mathrm{Zn}^{2+}$ ions. In the absorption of heavy water, the $v_{\mathrm{a}}\left(\mathrm{COO}^{-}\right)$singlet due to the wet state appears at the same position as in the case of normal water. This suggests that hydration takes place preferentially to $\mathrm{Zn}$ cation, not to the carboxylate groups. ${ }^{14}$

It is necessary to mention a remarkable difference in molar absorption coefficient of the $v_{\mathrm{a}}\left(\mathrm{COO}^{-}\right)$mode between the dry and wet states. $\varepsilon_{\text {wet }}$ is only one third of $\varepsilon_{\mathrm{dry}}$. As one of the origin of such a big difference, the dielectric field effect may be considered. In the case of E-MA-Zn, the intensity ratio of the $v_{\mathrm{a}}\left(\mathrm{COO}^{-}\right)$ bands in the dry and wet states is expressed according to the Polo-Wilson equation ${ }^{17}$ as

$$
\begin{aligned}
\left(\varepsilon_{\mathrm{wet}} / \varepsilon_{\mathrm{dry}}\right)= & \left(n_{\mathrm{dry}} / n_{\mathrm{wet}}\right)\left[\left(n_{\mathrm{wet}}^{2}+2\right)\right. \\
& \left./\left(n_{\mathrm{dry}}^{2}+2\right)\right]^{2}
\end{aligned}
$$

where $n_{\mathrm{dry}}$ and $n_{\text {wet }}$ are the refractive indices of the dry and wet states, respectively. In order to estimate the intensity ratio caused by this origin, the cases of $\mathrm{ZnSO}_{4}, \mathrm{CaCO}_{3}$, and their hydrates are considered. The averaged $n$ value of $\mathrm{ZnSO}_{4}$ is 1.666 and that of $\mathrm{ZnSO}_{4} \cdot 7 \mathrm{H}_{2} \mathrm{O}$ is 1.474 for $\lambda=589 \mathrm{~nm} .{ }^{18}$ The difference in $n$ between $\mathrm{ZnSO}_{4}$ and $\mathrm{ZnSO}_{4} \cdot 7 \mathrm{H}_{2} \mathrm{O}$ may be caused by the difference in the density. Assuming a linear relationship between $n$ and the hydration number, we evaluate $n$ as 1.652

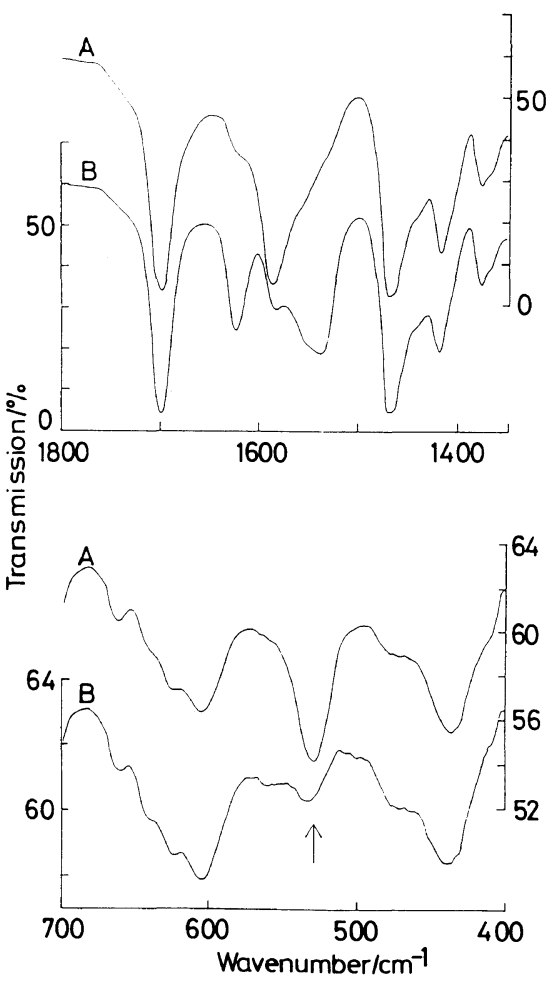

Figure 5. Spectral changes of $v_{\mathrm{a}}\left(\mathrm{COO}^{-}\right)$and $\mathrm{P}\left(\mathrm{COO}^{-}\right)$ (arrow) bands in wet (A) and dry (B) states.

for $\mathrm{ZnSO}_{4} \cdot(1 / 2) \mathrm{H}_{2} \mathrm{O}$. This value gives the ratio $\varepsilon_{\text {wet }} / \varepsilon_{\text {dry }}$ as 0.989 . From the values of $n$ for $\mathrm{CaCO}_{3} \quad(n=1.572)$ and $\mathrm{CaCO}_{3} \cdot \mathrm{H}_{2} \mathrm{O} \quad(n=$ 1.567) for $\lambda=589 \mathrm{~nm}^{18}$ the corresponding ratio is evaluated as 0.998 .

Thus, the dielectric field effect cannot interpret the big difference in absorptivity between the two states. Another origin may be related to the vibrational coupling of the $v_{\mathrm{a}}$ $\left(\mathrm{COO}^{-}\right)$and rocking $\mathrm{P}\left(\mathrm{COO}^{-}\right)$modes. In the dry state, there appears the triplet band due to the $v_{\mathrm{a}}\left(\mathrm{COO}^{-}\right)$and a weak $\mathrm{P}\left(\mathrm{COO}^{-}\right)$band at $530 \mathrm{~cm}^{-1}$. Appearance of the $v_{\mathrm{a}}\left(\mathrm{COO}^{-}\right)$singlet in the wet state is accompanied with an increase in the intensity ( $c a .5$ times) of the $\mathrm{P}\left(\mathrm{COO}^{-}\right)$ band (Figure 5), indicating that the $v_{\mathrm{a}}\left(\mathrm{COO}^{-}\right)$ and $\mathrm{P}\left(\mathrm{COO}^{-}\right)$vibrations couple with each other. Occurrence of the $v_{\mathrm{a}}\left(\mathrm{COO}^{-}\right)-\mathrm{P}\left(\mathrm{COO}^{-}\right)$ coupling seems reasonable since these modes 
have the transition moments nearly parallel to each other. In such case, complementally intensity changes may occur between the two modes.

It is noted that the characteristic spectral change in a $\mathrm{Zn}$ salt of an E-MA ionomer in the $v_{\mathrm{a}}\left(\mathrm{COO}^{-}\right)$region was induced only for a partially neutralized specimen. Coleman et al. studied the temperature dependence from 25 to $180^{\circ} \mathrm{C}$ in the $v_{\mathrm{a}}\left(\mathrm{COO}^{-}\right)$region for a $100 \%$ neutralized specimen but significant spectral change was not observed. We also examined the spectral change for a specimen completely neutralized according to the method of Coleman et al. Drying it at $60^{\circ} \mathrm{C}$ over $200 \mathrm{~h}$ did not cause the spectral change. This indicates that the $\mathrm{COOH}$ group plays an important role in this spectral feature.

Acknowledgment. The author is greatly indebted to Professor Masamichi Kobayashi of Osaka University for valuable discussions and encouragement.

\section{REFERENCES}

1. A. Eisenberg, Macromolecules, 3, 147 (1970).

2. A. Eisenberg, J. Polym. Sci., Polym. Symp. Ed., 45, 99 (1974).

3. G. B. Rouse, W. M. Risen, Jr., A. T. Tsatsas, and
A. Eisenberg, J. Polym. Sci., Polym. Phys. Ed., 17, 81 (1979).

4. D. G. Peiffer, B. L. Hager, R. A. Weiss, P. K. Agarwel, and R. D. Lundberg, J. Polym. Sci., Polym. Phys. Ed., 23, 1869 (1985).

5. A. Neppel, I. S. Butler, and A. Eisenberg, Macromolecules, 12, 948 (1979).

6. A. Neppel, I. S. Butler, and A. Eisenberg, J. Polym. Sci., Polym. Phys. Ed., 17, 2145 (1979).

7. A. Neppel, I. S. Butler, N. Brockman, and A. Eisenberg, J. Macromol. Sci.-Phys., B19, 61 (1981).

8. P. C. Painter, B. A. Brozoski, and M. M. Coleman, J. Polym. Sci., Polym. Phys. Ed., 20, 1069 (1982).

9. B. A. Brozoski, M. M. Coleman, and P. C. Painter, J. Polym. Sci., Polym. Phys. Ed., 21, 301 (1983).

10. B. A. Brozoski, M. M. Coleman, and P. C. Painter, Macromolecules, 17, 230 (1984).

11. B. A. Brozoski, P. C. Painter, and M. M. Coleman, Macromolecules, 17, 1591 (1984).

12. M. M. Coleman, J. Y. Lee, and P. C. Painter, Macromolecules, 23, 2339 (1990).

13. T. Ishioka and M. Kobayashi, Polym. Prepr. Jpn., 33, 2427 (1984).

14. T. Ishioka and M. Kobayashi, Rep. Prog. Polym. Phys. Jpn., 29, 195 (1986).

15. T. Ishioka and M. Kobayashi, Macromolecules, 23, 3183 (1990).

16. M. Kobayashi and S. Kawabata, Spectrochim. Acta, 33A, 549 (1977).

17. S. R. Polo and M. K. Wilson, J. Chem. Phys., 23, 2376 (1955).

18. Landort-Börnstein, "Zahlenwerte und Funktionen aus Physik, Chemie, Astoronomie, Geophysik und Technik," Sechste Auflage, II. Band, Eigenschaften der Materie in Ihren Aggregetzuständed, 8 Teil, Optische Konstanten, Springer-Verlag, Berlin, 1962. 